\title{
Occupational burnout among active physiotherapists working in clinical hospitals during the COVID-19 pandemic in south-eastern Poland
}

\author{
Bogumiła Pniak $^{\mathrm{a}}$, Justyna Leszczak ${ }^{\mathrm{b}, *}$, Marzena Adamczyk ${ }^{\mathrm{c}}$, Wojciech Rusek ${ }^{\mathrm{d}}$, Piotr Matłosz ${ }^{\mathrm{e}}$ \\ and Agnieszka Guzik ${ }^{\mathrm{b}}$ \\ ${ }^{a}$ Excelsior Health and Rehabilitation Hospital, Al. Torosiewicza, Iwonicz-Zdrój, Poland \\ ${ }^{\mathrm{b}}$ Institute of Health Sciences, Medical College, University of Rzeszów, Rzeszów, Poland \\ ${ }^{\mathrm{c}}$ RehaKlinika, Rzeszów, Poland \\ ${ }^{\mathrm{d}}$ Rehabilitation Center REHAMED-CENTER, Tajecina, Poland \\ e Institute of Physical Culture Sciences, Medical College, University of Rzeszów, Rzeszów, Poland
}

Received 10 September 2020

Accepted 29 November 2020

\begin{abstract}
.
BACKGROUND: Occupational burnout, which is more and more commonly encountered among medical professionals and investigated by researchers worldwide, may in particular affect health care workers during the COVID-19 pandemic.

OBJECTIVES: The aim of the study was to assess the risk of occupational burnout among physiotherapists working actively in clinical hospitals in south-eastern Poland during the COVID-19 pandemic.

METHODS: The level of burnout among the studied physiotherapists was assessed using the Polish version of the Maslach Burnout Inventory by Maslach (MBI). The study was conducted from 20 March to 3 May, 2020 among physiotherapists working professionally during the COVID-19 pandemic in the south east of Poland, during which time health services related to therapeutic rehabilitation were suspended. The study was conducted among 1,540 physiotherapists with a license to practice who worked in clinical departments. Considering the inclusion and exclusion criteria, 106 physiotherapists were qualified for the study.

RESULTS: The current findings show that during the COVID-19 pandemic physiotherapists present high burnout rates in all three dimensions: EE (Mean 32.31; CI 29.47-35.15); DP (Mean 16.25; CI 14.48-18.03); PA (Mean 26.25; CI 24.41-28.10). As for gender-related effects, higher burnout rates were observed in the male workers, compared to the females, in all three domains: EE (Men: Mean 34.70; CI 29.90-39.50 - Women: Mean 31.03; CI 27.45-34.60); DP (Men: Mean 18.78; CI 15.98-21.59 - Women: Mean 14.90; CI 12.64-17.16) and PA (Men: Mean 24.54; CI 21.32-27.76 - Women: Mean 27.17;
\end{abstract}

*Address for correspondence: Justyna Leszczak, PhD, Institute of Health Sciences, Medical College, University of Rzeszów, ul. Kopisto 2a, 35-959 Rzeszów, Poland. Tel.: +48 178721153; E-mail: leszczakjustyna.ur@gmail.com. 
CI 24.90-29.44). The highest burnout rates, presented by the physiotherapists working in the profession for more than 20 years, were identified in the domain of EE (Mean: 35.30; CI 30.51-40.10) and in those with 10-15 years of experience, in the domains of DP (Mean: 18.31; CI 14.89-21.73) and PA (Mean: 23.97; CI 20.13-27.81). The highest rate of occupational burnout, reflected by the scores in all three domains (EE, DP, PA), was identified in Department I - Intensive Care and Anaesthesiology Department: EE - (Mean: 40.89, CI 35.27-46.52); DP - (Mean: 21.39, CI 17.90-24.88); and PA - (Mean: 23.07, CI 20.04-26.10), compared to the other departments. The subjects who rarely participated in courses or training programs showed the highest burnout rates (EE- Mean: 33.55, CI 29.33-37.77; DP- Mean: 16.71, CI 13.99-19.43; PAMean: 25.45, CI 22.47-28.43).

CONCLUSIONS: Occupational burnout during the COVID-19 pandemic is noticeable among physiotherapists working in clinical departments. The current findings show high burnout rates in all three domains: emotional exhaustion (EE), depersonalization (DP) and personal accomplishment (PA). A comparative analysis of these findings with reference to related studies published before the pandemic shows that the burnout rates among physiotherapists may have significantly increased during the COVID-19 pandemic. However, given the scarcity of scientific evidence related to this specific problem in Poland and worldwide, it is necessary to continue research in occupational burnout affecting physiotherapists, particularly during the second wave of the pandemic, in order to gain a better understanding of the possible effects of social isolation and greater personal work-related health risks on the mental health of these medical professionals.

Keywords: Health workers, stress, coronavirus, SARS-CoV-2

\section{Introduction}

Work is a prerequisite for human existence. It defines our place in society, gives satisfaction and shapes personality. Work constantly enriches one's life with new challenges. The medical professions are particularly burdened with a high risk of negative effects from their professional life. The phenomenon of occupational burnout deserves special attention. It is characterized by many symptoms that are difficult to diagnose and are often mistaken for temporary fatigue [1-3].

Physiotherapists are a special professional group whose work involves not only physical effort, but also mental work. The task of a physiotherapist is to assist the patient in restoring the highest possible functional level. The degree of the physiotherapist's satisfaction with their work also affects the person undergoing rehabilitation [4]. A review of the literature indicates that work-related stress and burnout can have a significant impact on health and the effectiveness of daily work [5]. At this point in Poland there are no studies related to occupational burnout among physiotherapists during the COVID-19 pandemic. In addition, the authors of the present study are also physiotherapy practitioners and therefore they wanted to investigate this phenomenon in their community. In fact, the profession of physiotherapist has also been overlooked in international literature discussing occupational burnout syndrome. The available studies related to this focus on nurses, physicians and paramedics [6-8]. These observations provided the motivation for this study.
The first case of SARS-CoV-2 coronavirus infection was detected in November 2019 in the Chinese city of Wuhan. Afterwards, the epidemic spread all over the world, and the first case recorded in Poland was on March 4, 2020 [9]. Most people have mild symptoms or are even asymptomatic; however, the infection is potentially life-threatening to the elderly, especially those with chronic diseases [10-13]. In Poland, a state of epidemic was declared and has been in effect since March 20, 2020 [14]. COVID19 has not only become a major threat to health, but has also caused increased stress and aggravated depression [15]. Studies confirm that work during the coronavirus pandemic has become more stressful. For some, the pandemic means living in a constant state of uncertainty, for others it has caused loss of work and their means of livelihood. For many physiotherapists, March 21, 2020 was an important date in their professional life [14]. They were forced to suspend their work and close their offices. According to the National Chamber of Physiotherapists (KIF), as many as $75 \%$ of physiotherapists in Poland, i.e. about 50,000, suspended their services [16]. From May 4, 2020, when health services for therapeutic rehabilitation reopened, physiotherapists found themselves in a new, difficult reality [17].

Stress and uncertainty associated with the performance of professional activities caused noticeable burnout among physiotherapists. Burnout, according to Freudenberger, is "a state of exhaustion caused by excessive demands imposed by the environment and the individual oneself" [18]. Leiter and Maslach recognized that burnout is the body's response 
to work-related stress. They highlighted emotional exhaustion, depersonalization and a reduced sense of one's own accomplishments [19]. They conducted a study on occupational burnout among people performing challenging jobs. People working with emotional exhaustion syndrome are likely to be frustrated and unable to enjoy the benefits of their work.

Stress in the workplace can manifest itself in indecisiveness or impulsiveness, difficulty in establishing appropriate relationships between people and addiction. Accidents at work are often observed due to stress, which have consequences not only for the employee, but also for the workplace [20]. Long-term stress contributes to illness. The regulations imposed by the authorities in response to COVID-19 mandated very strict procedures and requirements, which in combination with fear of infection and isolation from loved ones led to stress and adversely affected mental health in many cases. Working in such conditions may aggravate the factors that cause depression and anxiety [18].

Occupational burnout is particularly related to professions connected with helping others, since they require specific social competences to be fully engaged. The work of a physiotherapist necessitates almost continuous contact with the patient. A professional role providing treatment, rehabilitation and patient care can be stressful as it requires direct contact with human suffering. Regular burdens are also aggravated by organizational errors in medical care, difficult working conditions, low wages and low professional status. These factors can lead to burnout [21-22].

During the pandemic, a large proportion of people have been unable to relieve tension, anxiety and stress through playing sport. This reduces their quality of life and their lack of motivation to act [23].

The consequence of burnout for an employee may be making mistakes, difficulty concentrating or frustration. It can also lead to physical fatigue, frequent absence from work and depression. Occupational burnout can have further negative impacts on family life [24]. Occupational burnout is a wider social problem, and therefore special attention has been paid to ways of dealing with it.

The issue of occupational burnout among medical professions has been covered in the literature more and more frequently; however, the impact of COVID19 on the quality of work of physiotherapists working in clinical hospitals has not been studied.

The aim of the study was to assess the risk of occupational burnout among physiotherapists working actively in clinical hospitals in south-eastern Poland during the SARS-CoV-2 outbreak.

\section{Methods}

The study was conducted among physiotherapists working during the COVID-19 pandemic in southeastern Poland. They were physiotherapists working at the Regional Clinical Hospital No. 1, Regional Clinical Hospital No. 2, Hospital of the Ministry of Internal Affairs and Administration and the Municipal Clinical Hospital. They were people working in the following clinical hospital departments: Department I - Intensive Care Unit and Anaesthesiology; Department II - Department of Orthopaedics and Motor Organ Traumatology; Department III - Department of Neurology. The study was conducted from March 20 to May 3, 2020, during the period when a state of epidemic was declared in Poland, when health services related to therapeutic rehabilitation were suspended.

\subsection{Study group}

In March 2020, a survey was sent out to 1,540 physiotherapists with a license to practice. 812 people took part in the study (returning the completed questionnaire). 659 people were excluded from the group because of a temporary suspension of work related to the pandemic or because they worked in departments other than: Intensive Care and Anaesthesiology, Orthopaedics and Motor Organ Traumatology, Neurology. Thirty-six physiotherapists were also excluded due to their age below 25 years (this criterion was specified because, typically, in Poland those graduating from Master's degree courses in physiotherapy and acquiring a license to work in the profession are 25 years old). Out of the remaining 117 questionnaires, 11 were excluded because they were completed incorrectly. Finally, 106 (37 male and 69 female) physiotherapists who were professionally active during the pandemic were included in the study (Fig. 1).

Criteria for inclusion: physiotherapist with a valid license to practice the profession and professionally active during the pandemic, working in a department of Intensive Care and Anaesthesiology, Orthopaedics and Motor Organ Traumatology or Neurology; aged between 25 and 60, completely filled out the on-line survey, and provided informed, voluntary consent to participate in the study. Exclusion criteria: lack of 


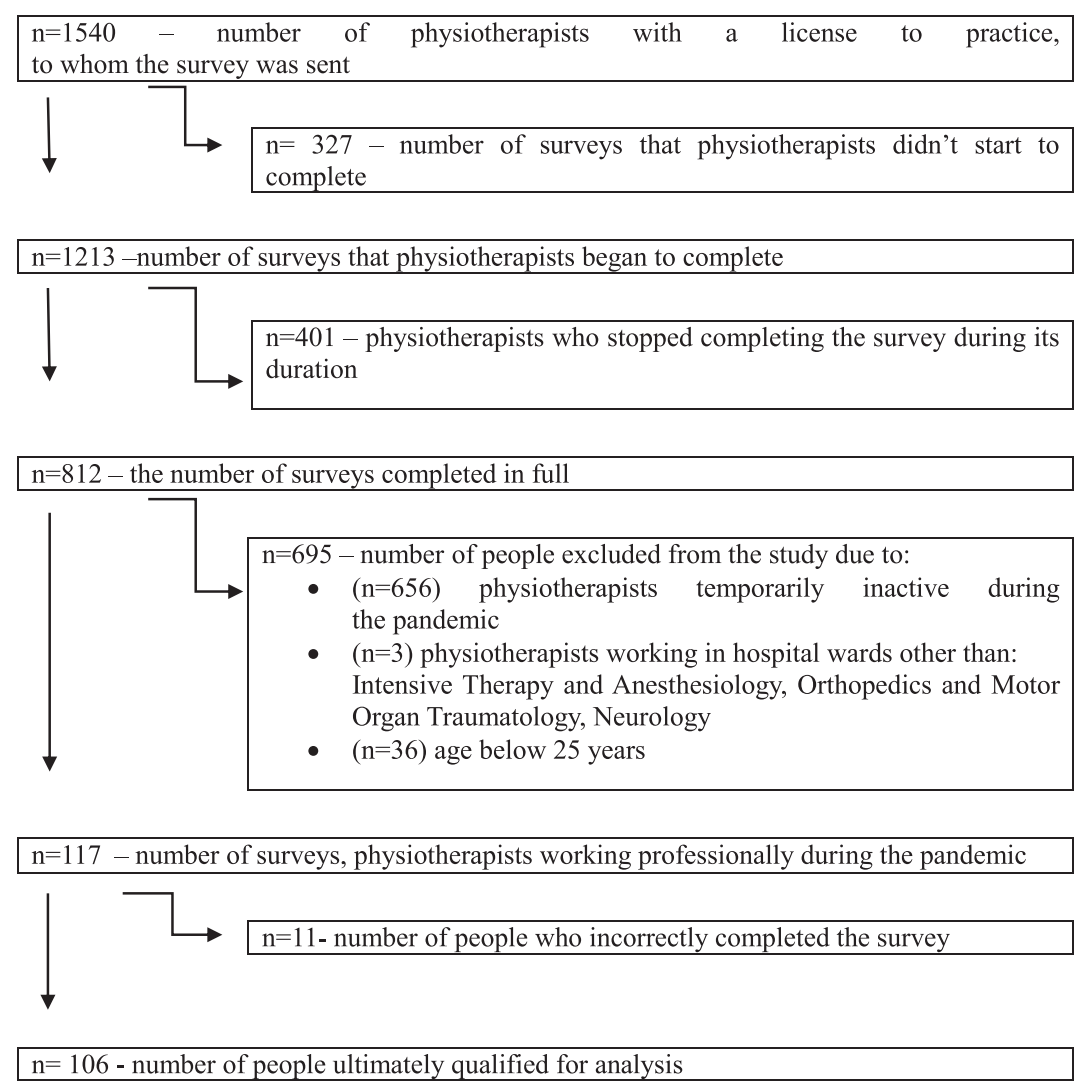

Fig. 1. Flowchart.

a valid license to practice, professionally inactive during the pandemic, working in hospital departments other than Intensive Care and Anaesthesiology, Orthopaedics and Motor Organ Traumatology, Neurology; aged below 25 or over 60 , lack of informed, voluntary consent to participate in the study, incomplete online survey.

\subsection{Research tools}

The level of burnout of the physiotherapists studied was assessed using the Polish version of the burnout questionnaire by Maslach (MBI), which has been adapted and verified by Pasikowski [25]. Due to the state of epidemic announced in Poland, the questionnaire was sent in the form of an online survey. The level of emotional exhaustion of the respondents, their level of depersonalization and the level of personal involvement in their work were considered in the questionnaire. Summarizing the categories listed, the burnout rate of the studied physiotherapists was indicated. All three categories, as well as the overall assessment of occupational burnout, were rated on a scale of 0 to 6 points, where a higher score indicated a greater intensity of a given issue. Burnout is confirmed by high scores obtained on the subscales of emotional exhaustion (EE, 9-54 points) and depersonalization (DP, 5-30 points) and low scores on the personal achievements subscale (PA, 8-48 points).

- Emotional Exhaustion (EE): questions 1-3, 6, 8, 13, 14, 16, 20-max. 54 points;

- Depersonalization (DP): questions 5, 10, 11, 15, 22- max. 30 points;

- Personal Accomplishment (PA): questions 4, 7, 9, 12, 17-19, 21-max. 48 points.

The score was calculated separately by adding the results obtained in each scale:

- EE - high (>27), moderate (17-26), low $(<16)$;

- DP - high ( $>13)$, moderate (7-12), low $(<6)$;

- PA- high (0-31), moderate (32-38), low (>39).

The higher the scores in the scales of EE and DP, the higher the level of burnout; conversely - in PA the lower the result, the higher the burnout rate. 


\subsection{Statistical analysis}

The analyses applied descriptive statistics (mean with $95 \%$ confidence interval, standard deviation, minimum value, maximum value, quartile I, quartile II). Statistical analysis was performed in the Statistica 13.1 program developed by StatSoft, and Microsoft Excel was used to present the results in a graphic form. The Mann-Whitney U test and Kruskal-Wallis ANOVA, classified as non-parametric tests, were used in the data analysis. These tests were applied because the data distribution and the sample size did not meet the criteria for parametric analysis. The level of statistical significance in this study was assumed at $p<0.05$.

\section{Results}

The current findings show that during the COVID19 pandemic physiotherapists present high burnout rates in all three dimensions: EE (Mean 32.31; CI 29.47-35.15); DP (Mean 16.25; CI 14.48-18.03); PA (Mean 26.25; CI 24.41-28.10) (Table 1).

Analyses focusing on the relationship between gender and occupational burnout showed the problem was more frequent among the male physiotherapists, compared to the females, which was reflected by the scores in all three domains, i.e. in EE (Men: Mean 34.70; CI 29.90-39.50 - Women: Mean 31.03; CI 27.45-34.60); in DP (Men: Mean 18.78; CI 15.98-21.59-Women: Mean 14.90; CI 12.64-17.16) and in PA (Men: Mean 24.54; CI 21.32-27.76 Women: Mean 27.17; CI 24.90-29.44). Irrespective of the above gender-related effects, it was observed that, overall, there was a high prevalence of occupational burnout among the physiotherapists (both female and male) working during the COVID-19 pandemic (Table 2).

The highest burnout rates were identified in physiotherapists who had been working in the profession for more than 20 years, in the domain of EE (Mean: 35.30; CI 30.51-40.10) and in those with 10-15 years of experience, in the domains of DP (Mean: 18.31; CI 14.89-21.73) and PA (Mean: 23.97; CI 20.13-27.81). Generally, the analyses focusing on the relationship between the duration of professional experience and occupational burnout showed a high prevalence of the problem in all of the groups of physiotherapists performing their job during the COVID-19 pandemic. Only the group of subjects with experience in the range of 5-10 years acquired moderate scores in the

Table 1

Assessment of the level of occupational burnout of physiotherapists based on the Maslach questionnaire

\begin{tabular}{lcccccccccc}
\hline $\begin{array}{l}\text { Questionnaire } \\
\text { Maslach }\end{array}$ & \multicolumn{10}{c}{ General burnout } \\
\cline { 2 - 11 } & $n$ & Mean & Cl-95\% & Cl+95\% & Median & Min. & Max. & Q1 & Q2 & SD \\
\hline EE & 106 & 32,31 & 29,47 & 35,15 & 35,50 & 0,00 & 54,00 & 22,00 & 45,00 & 14,75 \\
DP & 106 & 16,25 & 14,48 & 18,03 & 19,00 & 0,00 & 30,00 & 7,00 & 24,00 & 9,23 \\
PA & 106 & 26,25 & 24,41 & 28,10 & 25,00 & 8,00 & 44,00 & 17,00 & 35,00 & 9,56 \\
\hline
\end{tabular}

$\mathrm{n}$ - number of subjects; CI - confidence interval; Min - minimum value; Max -maximum value; Q1 - quartile I; Q2 - quartile II; SD - standard deviation.

Table 2

Assessment of the level of occupational burnout of physiotherapists based on the Maslach questionnaire depending on sex

\begin{tabular}{|c|c|c|c|c|c|c|c|c|c|c|c|}
\hline \multicolumn{2}{|c|}{ Questionnaire Maslach } & \multicolumn{10}{|c|}{ Burnout and sex } \\
\hline & & $n$ & Mean & $\mathrm{Cl}-95 \%$ & $\mathrm{Cl}+95 \%$ & Median & Min. & Max. & Q1 & Q2 & SD \\
\hline \multirow[t]{3}{*}{$\mathrm{EE}$} & Women & 69 & 31,03 & 27,45 & 34,60 & 34,00 & 2,00 & 54,00 & 21,00 & 43,00 & 14,88 \\
\hline & Men & 37 & 34,70 & 29,90 & 39,50 & 38,00 & 0,00 & 53,00 & 29,00 & 45,00 & 14,39 \\
\hline & $p$ & \multicolumn{10}{|c|}{$\mathrm{Z}=-1,28 p=0,202$} \\
\hline \multirow[t]{3}{*}{ DP } & Women & 69 & 14,90 & 12,64 & 17,16 & 15,00 & 0,00 & 30,00 & 6,00 & 23,00 & 9,41 \\
\hline & Men & 37 & 18,78 & 15,98 & 21,59 & 21,00 & 0,00 & 29,00 & 14,00 & 25,00 & 8,42 \\
\hline & $p$ & \multicolumn{10}{|c|}{$\mathrm{Z}=-1,90 p=0,058$} \\
\hline \multirow[t]{3}{*}{ PA } & Women & 69 & 27,17 & 24,90 & 29,44 & 27,00 & 10,00 & 44,00 & 19,00 & 35,00 & 9,45 \\
\hline & Men & 37 & 24,54 & 21,32 & 27,76 & 21,00 & 8,00 & 43,00 & 17,00 & 31,00 & 9,65 \\
\hline & $p$ & \multicolumn{10}{|c|}{$\mathrm{Z}=1,26 p=0,208$} \\
\hline
\end{tabular}

n - number of subjects; CI - confidence interval; Min - minimum value; Max - maximum value; Q1 - quartile I; Q2 - quartile II; SD standard deviation; Z - Mann-Whitney U test; $p$ - level of significance of differences. 
Table 3

Assessment of the level of occupational burnout of physiotherapists based on the Maslach questionnaire depending on their experience

\begin{tabular}{|c|c|c|c|c|c|c|c|c|c|c|c|}
\hline \multicolumn{2}{|c|}{ Questionnaire Maslach } & \multicolumn{10}{|c|}{ Burnout and experience of physiotherapists } \\
\hline & & $n$ & Mean & $\mathrm{Cl}-95 \%$ & $\mathrm{Cl}+95 \%$ & Median & Min. & Max. & Q1 & Q2 & $\mathrm{SD}$ \\
\hline \multirow[t]{5}{*}{$\mathrm{EE}$} & $5-10$ years & 31 & 25,97 & 19,70 & 32,24 & 23,00 & 0,00 & 54,00 & 10,00 & 42,00 & 17,09 \\
\hline & $10-15$ years & 29 & 35,14 & 30,01 & 40,27 & 37,00 & 4,00 & 52,00 & 33,00 & 45,00 & 13,49 \\
\hline & $15-20$ years & 23 & 34,30 & 28,12 & 40,49 & 39,00 & 0,00 & 53,00 & 22,00 & 45,00 & 14,30 \\
\hline & 20 and more & 23 & 35,30 & 30,51 & 40,10 & 35,00 & 8,00 & 53,00 & 28,00 & 45,00 & 11,09 \\
\hline & $p$ & \multicolumn{10}{|c|}{$\mathrm{H}=6,19 p=0,102$} \\
\hline \multirow[t]{5}{*}{ DP } & $5-10$ years & 31 & 13,32 & 9,66 & 16,99 & 12,00 & 0,00 & 30,00 & 5,00 & 24,00 & 9,99 \\
\hline & $10-15$ years & 29 & 18,31 & 14,89 & 21,73 & 21,00 & 0,00 & 29,00 & 13,00 & 25,00 & 8,98 \\
\hline & $15-20$ years & 23 & 16,96 & 13,07 & 20,84 & 20,00 & 3,00 & 30,00 & 6,00 & 24,00 & 8,98 \\
\hline & 20 and more & 23 & 16,91 & 13,34 & 20,49 & 19,00 & 3,00 & 29,00 & 10,00 & 23,00 & 8,27 \\
\hline & $p$ & \multicolumn{10}{|c|}{$\mathrm{H}=3,68 p=0,297$} \\
\hline \multirow[t]{5}{*}{ PA } & $5-10$ years & 31 & 29,65 & 26,06 & 33,23 & 33,00 & 12,00 & 43,00 & 19,00 & 37,00 & 9,78 \\
\hline & $10-15$ years & 29 & 23,97 & 20,13 & 27,81 & 22,00 & 12,00 & 44,00 & 16,00 & 29,00 & 10,09 \\
\hline & $15-20$ years & 23 & 25,52 & 21,49 & 29,56 & 23,00 & 8,00 & 43,00 & 19,00 & 34,00 & 9,33 \\
\hline & 20 and more & 23 & 25,30 & 21,83 & 28,77 & 25,00 & 10,00 & 43,00 & 18,00 & 31,00 & 8,03 \\
\hline & $p$ & \multicolumn{10}{|c|}{$\mathrm{H}=6,07 p=0,108$} \\
\hline
\end{tabular}

n - number of subjects; CI - confidence interval; Min - minimum value; Max - maximum value; Q1 - quartile I; Q2 - quartile II; SD standard deviation; $\mathrm{H}$ - Anova Kruskal-Wallis test; $p$ - level of significance of differences.

Table 4

Assessment of the level of occupational burnout of physiotherapists based on the Maslach questionnaire depending on the workplace

\begin{tabular}{|c|c|c|c|c|c|c|c|c|c|c|c|}
\hline \multicolumn{2}{|c|}{ Questionnaire Maslach } & \multicolumn{10}{|c|}{ Burnout and workplace } \\
\hline & & $n$ & Mean & $\mathrm{Cl}-95 \%$ & $\mathrm{Cl}+95 \%$ & Median & Min. & Max. & Q1 & Q2 & SD \\
\hline \multirow[t]{4}{*}{$\mathrm{EE}$} & Ward I*,** & 28 & 40,89 & 35,27 & 46,52 & 47,50 & 4,00 & 54,00 & 33,00 & 51,00 & 14,51 \\
\hline & Ward II* & 38 & 32,79 & 28,47 & 37,11 & 36,00 & 0,00 & 48,00 & 24,00 & 45,00 & 13,14 \\
\hline & Ward III** & 40 & 25,85 & 21,56 & 30,14 & 32,50 & 0,00 & 43,00 & 14,00 & 37,00 & 13,43 \\
\hline & $p$ & \multicolumn{10}{|c|}{$\mathbf{H}=\mathbf{2 2 , 3 1} p=\mathbf{0 , 0 0 0 0}$} \\
\hline \multirow[t]{4}{*}{ DP } & Ward I*,** & 28 & 21,39 & 17,90 & 24,88 & 26,00 & 0,00 & 30,00 & 14,50 & 28,00 & 9,00 \\
\hline & Ward II* & 38 & 16,82 & 14,08 & 19,55 & 19,00 & 0,00 & 28,00 & 13,00 & 24,00 & 8,32 \\
\hline & Ward III** & 40 & 12,13 & 9,44 & 14,81 & 9,00 & 1,00 & 25,00 & 5,00 & 21,00 & 8,41 \\
\hline & $p$ & \multicolumn{10}{|c|}{$\mathbf{H}=\mathbf{1 9 , 8 2} p=\mathbf{0 , 0 0 0 0}$} \\
\hline \multirow[t]{4}{*}{ PA } & Ward I & 28 & 23,07 & 20,04 & 26,10 & 22,00 & 8,00 & 43,00 & 17,50 & 27,00 & 7,82 \\
\hline & Ward II & 38 & 25,61 & 22,52 & 28,69 & 23,00 & 10,00 & 44,00 & 17,00 & 33,00 & 9,39 \\
\hline & Ward III & 40 & 29,10 & 25,84 & 32,36 & 31,50 & 12,00 & 43,00 & 17,00 & 37,00 & 10,20 \\
\hline & $p$ & \multicolumn{10}{|c|}{$\mathrm{H}=4,99 p=0,082$} \\
\hline
\end{tabular}

n - number of subjects; CI - confidence interval; Min - minimum value; Max - maximum value; Q1 - quartile I; Q2 - quartile II; SD standard deviation; $\mathrm{H}$ - Anova Kruskal-Wallis test; $p$ - level of significance of differences; ${ }^{*}$ and ${ }^{* *}$ pairs of variables that differ significantly at the level of $p<0.05$ in the post-hoc test (multiple comparisons). *difference between ward I and ward II, a ** between ward I and ward III; I - Intensive Care and Anaesthesiology Ward; II - Ward of Orthopedics and Traumatology; III - Ward of Neurology.

domain EE (Mean: 25.97; CI 19.70-32.24) reflecting the fact they were less affected by the problem (Table 3).

The results in the specific Maslach inventory scales show a high level of EE-related occupational burnout among the physiotherapists working in Department I (Intensive Care and Anaesthesiology Department) (Mean: 40.89, CI 35.27-46.52) and Department II (Orthopaedics and Traumatology) (Mean: 32.79, CI 28.47-37.11), compared to physiotherapists working in Department III (Neurology) (Mean: 25.85,
CI 21.56-30.14) who in this domain presented only moderate burnout. Likewise, DP-related burnout was high in the subjects working in Department I (Mean: 21.39, CI 17.90- 24.88) and Department II (Mean: 16.82, CI 14.08-19.55) and moderate in those working in Department III (Mean: 12.13, CI 9.44-14.81). The scores on the PA scale also showed high burnout in the physiotherapists working in Department I (Mean: 23.07, CI 20.04-26.10) and in Department II (Mean: 25,.61, CI 22.52-28.69) as well as in Department III (Mean: 29.10, CI 25.84-32,36). The highest 
Table 5

Assessment of the level of occupational burnout of physiotherapists based on the Maslach questionnaire depending on participation in courses or training to raise professional qualifications

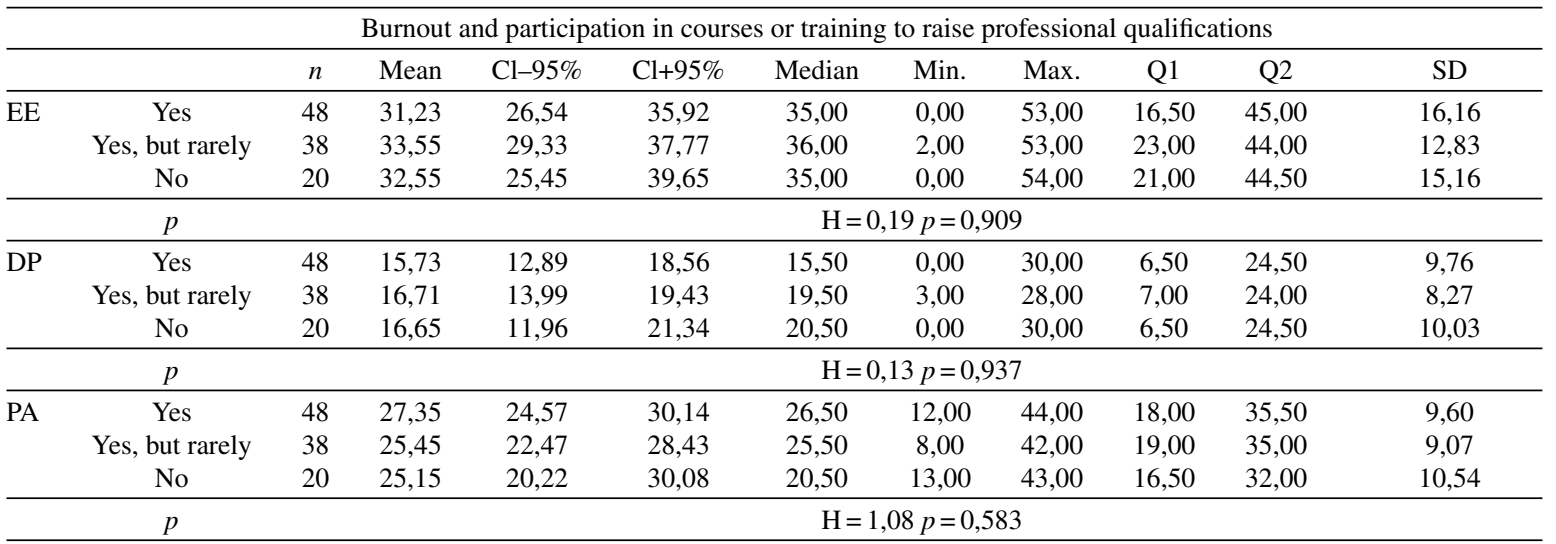

$\mathrm{n}$ - number of subjects; CI - confidence interval; Min - minimum value; Max - maximum value; Q1 - quartile I; Q2 - quartile II; SD standard deviation; $\mathrm{H}$ - Anova Kruskal-Wallis test; $p$ - level of significance of differences.

rate of occupational burnout, reflected by the scores in all three domains (EE, DP, PA), was identified in Department I (Table 4).

The findings show that high occupational burnout in all the domains is common among all the physiotherapists participating in this study; however, the subjects who rarely participated in courses or training programs showed the highest burnout rates (EEMean: 33.55, CI 29.33-37.77; DP- Mean: 16.71, CI 13.99-19.43; PA- Mean: 25.45, CI 22.47-28.43) (Table 5).

\section{Discussion}

Burnout syndrome has been a frequent subject of scientific study for many years. Numerous studies have been conducted in groups of teachers, firefighters, social workers, prison staff, doctors, nurses and paramedics [26-28]. However, there are few studies investigating the level of occupational burnout in a group of physiotherapists, and in particular during the COVID-19 pandemic. Kraczla [29] analysed occupational burnout syndrome and associated workplace stress, finding that burnout can be caused by longterm stress, which triggers adverse mechanisms, the adverse impact of the workplace and the environment, and its indifferent attitude towards the employee. Leiter and Maslach [19] emphasized that there must be a balance between stressors and support from the organizational environment. They indicated as the main factor excessive workload and obligations related to it. Low pay and lack of an incentive system can also cause burnout syndrome.
Healthcare workers are particularly vulnerable to long-term stress during the COVID-19 pandemic [30].

A study of nurses by Kowalczuk et al. [31] showed that they tend to be satisfied with their profession, but also that their work is stressful. Stress factors for them included low salaries and sudden deterioration of patients' health, which is also the case in other medical professions. Załuski and Makara-Studzińska [32] noticed in their study that nurses may also have a very emotional approach to their work, and this can lead to various negative consequences. In particular, 2020 became a year of increased stress for nurses and midwives due to the COVID-19 pandemic. Al-Mandhari et al. pointed out that occupational burnout syndrome during the pandemic is also intensified by the fact that health professionals may be separated from their families [33]. Furthermore, Zerbili et al. reported a higher level of stress and burnout among nurses working on COVID-19 wards, compared to their colleagues working on regular wards. Physicians reported similar scores regardless of their contact with COVID-19 patients. The most common causes for burden were job strain and uncertainty about the future [34].

Makara-Studzińska et al. [35] conducted a study among a group of doctors and medical staff at risk of occupational burnout. The most stressful factors in the group of examined doctors was short professional experience, a large number of duties and a small number of days off. Simons and Baldwin [36] showed that the problem of burnout clearly exists among Polish medical professionals and that it certainly requires attention from society, health policy leaders, and doctors themselves. Simons and Baldwin [37] in their 
study observed that during the COVID-19 outbreak, doctors who have already retired, as well as those who have become burned out, were asked to return to treatment in the fight against the coronavirus. Not all healthcare professionals agree to do so. They feel anxiety and fear of the "invisible opponent" with which they are forced to fight. Doctors often refuse to take up professional activity again as they are worried about their families.

Pavlakis et al. [38] proved that physiotherapists' profession is stressful, especially for those employed in public facilities and for women. Occupational burnout in female physiotherapists was also studied by Makara-Studzińska et al. [39]. They report that women show low satisfaction with their work and life as physiotherapists, caused by chronic fatigue and physical exhaustion. In the study group, the authors found that the risk factors were high demands placed on employees, stress, low pay and lack of promotion prospects. In our study, more frequent burnout was observed among men. Research carried out during the COVID-19 pandemic among health care workers showed that women were nearly twice as likely to report feelings of isolation as men [40]. Likewise, according to Civantos et al., occupational burnout affects women more frequently than men [41].

In a study conducted by Puszczałowska-Lizis et al. [42] potential risk factors for occupational burnout of physiotherapists were analysed. The study was conducted among 102 physiotherapists working in various facilities. Burnout was analysed in relation to gender, age and experience, the effect of the workplace and the amount of time spent on rest. A higher burnout rate was demonstrated for people aged 35-40 and with more than 10 years of experience. The level of professional satisfaction was lower among physiotherapists who did not participate in vocational training and did not engage in physical activity. Similarly, in our study, a higher rate of burnout was observed for physiotherapists who had been working in the profession for over 10 years (the groups from 10-15 years and over 20 years).

Kowalska [43] conducted a study among 64 professionally active physiotherapists who worked with patients with various ailments. She observed that mental exhaustion is noticeable in physiotherapists working with neurological and orthopaedic patients. Physical work with these patients, i.e. using mainly kinesitherapy, causes an increase in negative attitudes towards patients. Taking up additional work also affects burnout. It was also noted that physiotherapists working with only one group of patients, or with a chronically ill patient who did not show progress in their rehabilitation, more often showed dissatisfaction with their work. Kowalska's study shows that physiotherapists are less exposed to burnout than other groups of public service professions. In our study, a divergence in occupational burnout was noticed depending on the hospital department in which the physiotherapists worked. Occupational burnout was more frequent in physiotherapists working in the Intensive Care and Anaesthesiology Department. A difference in the incidence of occupational burnout was noticed in a study by Bejer et al. [44], who showed that the highest occupational burnout, with respect to the emotional sphere, was observed in physiotherapists working in healthcare homes. Stelcer and Bilski [45] also noted that occupational burnout often occurs in people working in palliative care.

Bartkowiak [3] believes that continuous improvement of qualifications is essential for the medical professions. On the other hand, Sęk [46] points out that burnout can be avoided if one is convinced of the effectiveness of one's goals. The most numerous group of respondents were physiotherapists with a master's degree, and a large group attended training courses regularly. In our study, during the COVID-19 pandemic, no effect on burnout was observed of raising professional qualifications through courses and training.

Occupational burnout among healthcare professionals is linked to the mental state of the staff. During the COVID-19 pandemic, given the threat of the virus, and the effect of the situation on mental health, it is crucial to protect healthcare workers from the adverse psychological effects of the pandemic. Interventions around the world began to implement psychological resistance intervention, based on various models and packages, to prevent depression among healthcare professionals [47, 48].

A review of the international literature shows there are no studies investigating occupational burnout among physiotherapists during the COVID-19 pandemic. Research carried out before the pandemic showed that the problem was indeed visible in this community; however, a comparison of the earlier evidence with the current findings (acquired during the pandemic) shows a significant increase in the incidence of burnout [44, 49]. Therefore, the present study provides very important insight to support the proper functioning of clinical facilities. The staff should be supported physically (by providing them with appropriate personal protection equipment) as 
well as mentally. Mental support can help prevent pre-term burnout as well as mental illness. Continuing research among healthcare professionals during the COVID-19 pandemic is justified and necessary.

\section{Limitations}

The current study presents certain limitations. Firstly, the study is based on short-term observations carried out during the pandemic and does not take into account possible occupational burnout affecting the subjects before the pandemic. However, since the COVID-19 pandemic is rapidly spreading in Poland, another study being currently conducted involves an observation period of more than six weeks and is designed to take into account occupational burnout from the period before the pandemic. Another limitation is connected with the lack of sample size calculation. This is linked with the fact that the decision to carry out this research was taken spontaneously in response to the pandemic which broke out in our country with little warning, affecting the whole of society and the functioning of people of all professions, including physiotherapists. Given the above, further research in this area is necessary; it should involve a larger study group and take into account various medical professions as well as other factors, such as age or gender. Another limitation of the study is linked with the nonparametric data distribution since the analyses of variables did not meet the normality condition.

\section{Conclusions}

Occupational burnout during the COVID-19 pandemic is noticeable among physiotherapists working in clinical departments. The current findings show high burnout rates in all three domains: emotional exhaustion (EE), depersonalization (DP) and personal accomplishment (PA). A comparative analysis of these findings with reference to related studies published before the pandemic shows that the burnout rates among physiotherapists may have significantly increased during the COVID-19 pandemic. However, given the scarcity of scientific evidence related to this specific problem in Poland and worldwide, it is necessary to continue research in occupational burnout affecting physiotherapists, particularly during the second wave of the pandemic, in order to gain a better understanding of the possible effects of social isolation and greater personal work-related health risks on the mental health of these medical professionals.

\section{Acknowledgments}

The authors would like to thank the respondents who devoted their time to take part in the study during such a difficult period as the COVID-19 pandemic.

\section{Conflict of interest}

The authors declare no conflict of interest.

\section{Funding}

This research received no external funding.

\section{References}

[1] Melé D. Understanding Humanistic Management. Humanist Manag J. 2016;1:33-55. doi.10.1007/s41463-016-0011-5

[2] Reith TP. Burnout in United States Healthcare Professionals: A Narrative Review. Cureus. 2018;10(12):e3681. doi: $10.7759 /$ cureus. 3681

[3] Bartkowiak G. Theoretical issues of human resource management in healthcare facilities. UM Poznań, Poznań 2004.

[4] Lee SE, Dahinten SV, MacPhee M. Psychometric evaluation of the McCloskey/Mueller Satisfaction Scale. Jpn J Nurs Sci. 2016;13:487-95. doi.10.1111/jjns. 12128

[5] Mikołajewska E. Work-related stress and burnout in physiotherapists - A literature review. Med Pr. 2014;65(5):693701. doi.10.13075/mp.5893.00078

[6] Wu Y, Wang J, Luo C, Hu S, Lin X, Anderson AE, et al. A Comparison of Burnout Frequency Among Oncology Physicians and Nurses Working on the Frontline and Usual Wards During the COVID-19 Epidemic in Wuhan, China. J Pain Symptom Manage. 2020;60(1):e60e65. doi:10.1016/j.jpainsymman.2020.04.008

[7] Luceño-Moreno L, Talavera-Velasco B, García-Albuerne Y, Martín-García J. Symptoms of Posttraumatic Stress, Anxiety, Depression, Levels of Resilience and Burnout in Spanish Health Personnel during the COVID-19 Pandemic. Int J Environ Res Public Health. 2020;17(15):5514. doi: 10.3390/ijerph17155514

[8] Matsuo T, Kobayashi D, Taki F, Sakamoto F, Uehara Y, Mori N, et al. Prevalence of Health Care Worker Burnout During the Coronavirus Disease 2019 (COVID-19) Pandemic in Japan. JAMA Netw Open. 2020;3(8):e2017271. doi:10.1001/jamanetworkopen.2020.17271

[9] Ministry of Health, Statistics Poland. Available online: https://www.gov.pl/web/zdrowie/pierwszy-przypadek-kor onawirusa-w-polsce (accessed on 4 May 2020).

[10] Wang L, Gao YH, Lou LL, Zhang GJ. The clinical dynamics of 18 cases of COVID-19 outside of Wuhan, 
China. Eur Respir J. 2020;55(4):2000398. doi.10.1183/ 13993003.00398-2020

[11] Chen N, Zhou M, Dong X, Qu J, Gong F, Han Y, et al. Epidemiological and clinical characteristics of 99 cases of 2019 novel coronavirus pneumonia in Wuhan, China: a descriptive study. Lancet. 2020;359(10223):50713. doi.10.1016/S0140-6736(20)30211-7

[12] Wang D, Hu B, Hu C, Zhu F, Liu X, Zhang J, et al. Clinical characteristics of 138 hospitalized patients with 2019 novel coronavirus-infected pneumonia in Wuhan, China. JAMA. 2020;323(11):1061-9. doi.10.1001/jama.2020.1585

[13] Baj J, Karakuła-Juchnowicz H, Teresiński G, Buszewicz G, Ciesielka M, Sitarz E, et al. COVID-19: Specific and Non-Specific Clinical Manifestations and Symptoms: The Current State of Knowledge. J. Clin. Med. 2020;9(6):1753. doi. $10.3390 / \mathrm{jcm} 9061753$

[14] Ministry of Health. Available online: http://isap.sejm.gov. pl/isap.nsf/download.xsp/WDU20200000491/O/D20200 491.pdf (accessed on 4 May 2020).

[15] Christopher DJ, Isaac BT, Rupali P, Thangakunam B. Health-care preparedness and health-care worker protection in COVID-19 pandemic. Lung India. 2020;37(3):238-45. doi.10.4103/lungindia.lungindia_189_20

[16] National Chamber of Physiotherapists- KIF. Available online: https://kif.info.pl/dramatyczna-sytuacja-fizjoterap eutow-alarmujemy-rzad-i-parlament/ (accessed on 4 May 2020).

[17] Ministry of Health. Available online: https://tvn24.pl/na jnowsze/wxmr56-Rozporz\%C4\%85dzenie-Rady-Ministr $\% \mathrm{C} 3 \%$ B3w-z-dnia-2-maja-2020-roku/Rozporz\%25C4\% 2585dzenie+z+2+maja+2020.pdf (accessed on 4 May 2020).

[18] Freudenberger HJ. Staff Burn-Out. Journal of Social Issues. 1974;30(1):159-65. doi.10.1111/j.1540-4560.1974. tb00706.x

[19] Leiter MP, Maslach C. Burnout and Engagement: Contributions to a New Vision. Burnout Res. 2017;5:55-7. doi.10.1016/j.burn.2017.04.003

[20] Litzke M, Schuh H. Stress, lobbying and burnout. GWP Gdańsk, Gdańsk 2007.

[21] Gold JA. COVID-19: adverse mental health outcomes for healthcare workers. BMJ. 2020;369:m1815. doi.10. 1136/bmj.m1815

[22] Luken M, Sammons A. Systematic Review of Mindfulness Practice for Reducing Job Burnout. Am J Occup Ther. 2016;70(2):7002250020p1-7002250020p10. doi.10. 5014/ajot.2016.016956

[23] Viana RB, de Lira CAB. Exergames as Coping Strategies for Anxiety Disorders During the COVID-19 Quarantine Period. Games Health J. 2020;9(3):147-9. doi. $10.1089 / \mathrm{g} 4 \mathrm{~h} .2020 .0060$

[24] Pieniążek M, Mańko G, Skupień J. Physiotherapist's work at the Oncological Ward - stress and professional burnout. Med Rehabil. 2017;21(3):35-42. doi.10. 5604/01.3001.0011.6813

[25] Pasikowski T. Polish adaptation of the questionnaire Maslach Burnout Inventory. W: Sęk H., red. Burnout. Causes, mechanisms, prevention. PWN, Warszawa. 2000; 135-48.

[26] Adler P. Market, Hierarchy and Trust. The Knowledge Economy and the Future of Captalism. Organization Science. 2001;12(2):215-34. doi.10.1287/orsc.12.2.215.10117

[27] Leitner MP, Harvie PL. Burnout among mental health workers: A test of the job demands - control model.
Int J Soc Psychiatry. 1996;42(2):90-101. doi.10.1177/002 076409604200203

[28] Topa G, Jurado-Del Pozo JF. Emotional Exhaustion and Health Complaints as Indicators of Occupational Diseases Among Civil Servants in Spain. J Clin Med. 2018;7(12):523. doi. $10.3390 / \mathrm{jcm} 7120523$

[29] Kraczla M. Professional burnout as a long term stress effect. College's Scientific Notebooks Humanitas. 2013;2:75-80. https://www.sbc.org.pl/publication/102309.

[30] El-Hage W, Hingray C, Lemogne C, Yrondi A, Brunault $\mathrm{P}$, Bienvenu T. et al. Les professionnels de santé face á la pandémie de la maladie á coronavirus (COVID-19): quels risques pour leur santé mentale? [Health professionals facing the coronavirus disease 2019 (COVID-19) pandemic: What are the mental health risks?]. Encephale. 2020;46(3S):S0013-7006(20)30076-2. doi.10.1016/j.en cep. 2020.04 .008

[31] Kowalczuk K, Zdańska A, Krajewska-Kułak E, łukaszczuk C, Van Damme-Ostapowicz K, Klimaszewska K, et al.. Stress in the work of nurses as a risk factor for burnout. Nursing Topics. 2011;3(19):307-14.

[32] Załuski M, Makara-Studzińska M. The reciprocal relationship between occupational burnout, emotional labor and work engagement in healthcare specialists. Med Pr. 2019;70(6):711-22. doi.10.13075/mp.5893.00868

[33] Al-Mandhari A, Gedik FG, Mataria A, Oweis A, Hajjeh R. 2020 - the year of the nurse and midwife: a call for action to scale up and strengthen the nursing and midwifery workforce in the Eastern Mediterranean Region. East Mediterr Health J. 2020;26(4):370-1. doi.10.26719/2020.26.4.370

[34] Zerbini G, Ebigbo A, Reicherts P, Kunz M, Messman $\mathrm{H}$. Psychosocial burden of healthcare professionals in times of COVID-19 - a survey conducted at the University Hospital Augsburg. Ger Med Sci. 2020;18:Doc05. doi.10.3205/000281

[35] Makara-Studzińska M, Tylec A, Kudlik A, Matuszczyk M, Murawiec S. Burnout syndrome among psychiatrists - literature review. Psychiatry. 2018;15(1):35-8.

[36] Zgliczyńska M, Zgliczyński S, Ciebiera M, KosińskaKaczyńska K. Occupational Burnout Syndrome in Polish Physicians: A Systematic Review. Int J Environ Res Public Health. 2020;16(24):5026. doi.10.3390/ijerph16245026

[37] Simons G, Baldwin DS. COVID-19: doctors must take control of their wellbeing. BMJ. 2020;369:m1725. doi.10.1136/bmj.m1725

[38] Pavlakis A, Raftopoulos V, Theodorou M. Burnout syndrome in Cypriot physiotherapists: a national survey. BMC Health Serv Res. 2010;10:63. doi.10.1186/1472-6963-1063

[39] Makara -Studzińska M, Krys -Noszczyk, K, Starczyńska M, Kiebzak W, Śliwiński Z. Occupational burnout and satisfaction with life in female physiotherapists. Polish Journal of Physiotherapy. 2012;12:327-39.

[40] Kelker H, Yoder K, Musey P, Harris M, Johnson O, Sarmiento E, et al. Longitudinal Prospective Study of Emergency Medicine Provider Wellness Across Ten Academic and Community Hospitals During the Initial Surge of the COVID-19 Pandemic. Res Sq. 2020:rs.3.rs-87786. doi.10.21203/rs.3.rs-87786/v1

[41] Civantos AM, Byrnes Y, Chang C, Prasad A, Chorath K, Poonia SK, et al. Mental health among otolaryngology resident and attending physicians during the COVID-19 pandemic: National study. Head Neck. 2020;42(7):1597609. doi: 10.1002/hed.26292 
[42] Puszczałowska -Lizis E, Niebieszczańska M, Jandziś S, Kiljański M. The Analysis of Potential Risks Factors for Professional Burnout Syndrome in Physiotherapists. Polish Journal of Physiotherapy. 2015;2(15):12-13. http:// fizjoterapiapolska.pl/article/analiza-potencjalnych-

czynnikow-ryzyka-syndromu-wypalenia-zawodowego-ufizjoterapeutow-the-analysis-of-potential-risks-factors-forprofessional-burnout-syndrome-in-physiotherapists/.

[43] Kowalska J. Professional burnout in polish physiotherapists. Advances in Rehabilitation. 2011;25(3):43-52. doi. 10.2478/rehab-2013-0014

[44] Bejer A, Domka-Jopek E, Probachta M, Lenart-Domka E, Wojnar J. Burnout syndrome in physiotherapists working in the Podkarpackie province in Poland. Work. 2019;64(4):809-815. doi.10.3233/WOR-193042

[45] Stelcer B, Bilski B. The phenomenon of job stress and burnout syndrome in palliative care. Med Pr. 2020;71(1):6978. doi.10.13075/mp.5893.00852
[46] Sęk H. Cognitive appraisal and competence as determinants of burnout in helping professions. Post Psychiatr Neurol. 2005;14(2):93-98. https://pracownik.kul.pl/ files/93237/public/wypalenie/sek_helena.pdf

[47] Albott CS, Wozniak JR, McGlinch BP, Wall MH, Gold BS, Vinogradov S. Battle Buddies: Rapid Deployment of a Psychological Resilience Intervention for Healthcare Workers during the COVID-19 Pandemic. Anesth Analg. 2020;131(1):43-54. doi.10.1213/ANE.0000000000004912

[48] Blake H, Bermingham F, Johnson G, Tabner A. Mitigating the Psychological Impact of COVID-19 on Healthcare Workers: A Digital Learning Package. Int J Environ Res Public Health. 2020;17(9):E2997. doi. 10.3390/ijerph17092997

[49] Pustułka-Piwnik U, Ryn Z J, Krzywoszański 1, Stożek J. Burnout syndrome in physical therapists - Demographic and organizational factors. Med Pr. 2014;65(4):453-62. doi. $10.13075 / \mathrm{mp} .5893 .00038$ 